\title{
Real-Time Monitoring Technology of Plaster-Based Three-Dimensional Printing System for Quality Determination of Model Structure
}

\author{
Min-Wei Hung ${ }^{1,2}$, Hsin-Yi Tsai ${ }^{1}$, Kuo-Cheng Huang ${ }^{1, *}$, \\ J. Andrew Yeh ${ }^{1,2}$ and Keng-Liang $\mathrm{Ou}^{3}$ \\ 'Instrument Technology Research Center, \\ National Applied Research Laboratories, Hsinchu 30076, Taiwan \\ ${ }^{2}$ Institute of NanoEngineering \& Microsystems, National Tsing Hua University, \\ Hsinchu 30076, Taiwan \\ ${ }^{3}$ Graduate Institute of Biomedical Materials and Tissue Engineering, \\ Taipei Medical University, Taipei 11031, Taiwan
}

(Received July 30, 2014; accepted March 9, 2015)

Key words: real-time monitoring, three-dimensional printing, near-infrared light, calcium phosphate, setting time, diffusion ratio

Using plaster-based three-dimensional printing (3DP) technology, calcium phosphate powder can be bonded together and become a model when a liquid adhesive is injected into the powder. This technology has many advantages, such as no need for support materials and fast setting times. However, the accuracy, surface flatness, and resolution of this technology are not equal to those of other manufacturing processes. These parameters can be analyzed from an image of each layer using a real-time monitoring module. Hence, in this study, light-emitting diode (LED) lights with four different wavelengths were used to irradiate a working platform, and the contour of the bonded region was obtained from images before and after the adhesive injection. The results show that the model irradiated by ultraviolet (UV) light $(405 \mathrm{~nm})$ has a higher image contrast from the powder than the model irradiated by visible (VIS) light (660 nm) and near-infrared (NIR) light $(890 \mathrm{~nm})$, the contrast rate of which was 0.92 . In addition, four volumes and four viscosities of adhesive were used to investigate the setting time and diffusion ratio of the model. The diffusion ratio was approximately $1.37 \pm 0.04$ times using four volumes of adhesive, but the setting time was in conjunction with the adhesive volume. In addition, the diffusion ratio of the model increased with the viscosity of the adhesive, which increased from 1.39 to 1.60 times and extended $70 \mathrm{~s}$ for setting compared with that with an adhesive without stickiness. By using a real-time monitoring system, the accuracy and quality of the model can be immediately controlled in the 3DP process, and the printing process can be interrupted to prevent wasting the material if the model becomes seriously distorted.

*Corresponding author: e-mail: huangkc@narlabs.org.tw 


\section{Introduction}

Three-dimensional printing (3DP) employs additive manufacturing (AM) technology to fabricate an object by building layer upon layer successively. Different from the traditional computer numerical control (CNC) machining technology, which removes material to fabricate a model, the materials in AM technology are added and joined by the printing head, which moves automatically to define the contour and shape of the model. Currently, the 3DP process is divided into five main types:(1) (1) fused deposition modeling (FDM), (2) (2) plaster-based 3DP (3DP $\left.{ }^{\mathrm{TM}} / \mathrm{PGP}\right),{ }^{(3)}$ (3) laminated object modeling (LOM), ${ }^{(4)}$ (4) stereo lithography apparatus (SLA), ${ }^{(5)}$ and (5) selective laser sintering (SLS). ${ }^{(6)}$ Among these, FDM is widely applied in object proofing and in the do-it-yourself (DIY) model, and it has advantages of lower cost and higher speed compared with other processes. SLS has the advantage of producing a model with high strength, but the temperature of the processing environment is extremely high. $3 \mathrm{DP}^{\mathrm{TM}}$ is widely employed in bone reconstruction, such as jawbone and spine reconstruction for biomedical and clinical research, ${ }^{(7,8)}$ for which the material is calcium phosphate cement (CPC) and no supporting material is needed in the printing process.

Owing to traumatic accidents and disease, there are millions of patients worldwide who need to undergo bone grafting surgery annually. Besides autografting from the patient's own bone, allografting from donors or bone-substitute materials is considered a second option. ${ }^{(9,10)}$ CPC is one of the bone-substitute materials in the field of bone reconstruction engineering in clinical applications owing to its excellent biocompatibility, modeling capability, and good manipulation. ${ }^{(11)}$ Specifically, CPCs can be replaced by human bone over time and without any disadvantages, and the time required for surgery with implantation bone cement is five times less than that required for autografting. Several types of CPCs were investigated to increase the modeling strength and setting time by adjusting the composition of CPCs. For example, calcium sulphate cement (CSC) is another bone-substitute material, which can be blended together with CPC in different proportions. Guo et al. ${ }^{(12)}$ investigated a new type of composite bone cement by mixing CSC and CPC, and the setting time of the model was 5-20 min. The results showed that the compressive strength of the cement increased with decreasing CSC content, but the degradation rate of composite cements increased with time when the CSC content was more than $20 \%$. Moreover, the bioactivity of the composite cement can be improved and enhanced by increasing CSC content, and the composite material has a suitable mechanical strength that can be widely employed in clinical cement. Gisep and $\mathrm{Rahn}^{(13)}$ used calcium-sulphate hemidydrate and monocalcium-phosphate monohydrate as the materials of ceramic cement, and employed four solutions as the adhesive in the setting process. The results showed that the shortest setting time of about 12 min can be obtained by adding distilled water to the cements, but this sample has the weakest compression strength. In addition, the highest compression strength, $5.9 \pm 1.5 \mathrm{MPa}$, can be obtained when the adhesive is glucose, but the setting time is $74 \mathrm{~min}$.

Even composite cements are used as the material in the $3 \mathrm{DP}^{\mathrm{TM}}$ system for jawbone or spine reconstruction, but few studies are related to the real-time technology in the 3DP ${ }^{\mathrm{TM}}$ process. In addition, the adhesive plays an important role in the $3 \mathrm{DP}^{\mathrm{TM}}$ system, which 
includes different types such as colloids, nanoparticles, and organic substances, and has different characteristics in clinical or biomedical applications. ${ }^{(14,15)}$ Hence, in this study, we built a real-time monitoring system with four wavelengths of light to irradiate a working platform and obtain images before and after an adhesive is added into a powder bed of calcium sulfate cement. By this method, the contour of the bonding region could be obtained from the intensity variation of two images. Moreover, to avoid the model's distortion, the diffusion ratio, the diffusion length of the bonding region, and the setting time of the model in relation to the volumes and viscosities of the adhesive were also evaluated.

\section{Materials and Methods}

\subsection{Material and properties}

The calcium sulfate can be divided into three types: anhydrite, bassanite, and gypsum, on the basis of the concentration of $\mathrm{H}_{2} \mathrm{O}$. The chemical formulas of the three types of calcium sulfate and their properties are summarized in Table 1. Bassanite has $0.5 \mathrm{H}_{2} \mathrm{O}$ per $\mathrm{CaSO}_{4}$ unit; it transforms into gypsum when water is introduced at room temperature, as expressed in eq. (1).

$$
\mathrm{CaSO}_{4} \cdot 0.5 \mathrm{H}_{2} \mathrm{O}+1.5 \mathrm{H}_{2} \mathrm{O} \rightarrow \mathrm{CaSO}_{4} \cdot 2 \mathrm{H}_{2} \mathrm{O}
$$

In addition, gypsum can be dehydrated by heating to $100-150{ }^{\circ} \mathrm{C}$, and the water becomes steam; the reaction is expressed in eq. (2).

$$
\mathrm{CaSO}_{4} \cdot 2 \mathrm{H}_{2} \mathrm{O}+\mathrm{Heat} \rightarrow \mathrm{CaSO}_{4} \cdot 0.5 \mathrm{H}_{2} \mathrm{O}+1.5 \mathrm{H}_{2} \mathrm{O}
$$

From the spectral features of calcium sulfate, Bishop et al. ${ }^{(16)}$ and Harrison ${ }^{(17)}$ found that bassanite has a lower light reflectance than gypsum in the visible (VIS) region, as shown in Fig. 1. This difference decreased with increasing wavelength, and they are close to each other at $800-900 \mathrm{~nm}$. In addition, water has a higher light reflectivity at $400-500 \mathrm{~nm},{ }^{(18)}$ and the light is fully absorbed in the near-infrared (NIR) region, as shown in Fig. 2. On the basis of this concept, four different wavelengths of light were selected to investigate the contour of the bonding region of gypsum in comparison with those of bassanite and water.

Table 1

Types of calcium sulfate and their properties.

\begin{tabular}{lccc}
\hline Property & Anhydrite & Bassanite & Gypsum \\
\hline Chemical formula & $\mathrm{Ca}\left(\mathrm{SO}_{4}\right)$ & $\mathrm{Ca}\left(\mathrm{SO}_{4}\right) \cdot 0.5 \mathrm{H}_{2} \mathrm{O}$ & $\mathrm{Ca}\left(\mathrm{SO}_{4}\right) \cdot 2 \mathrm{H}_{2} \mathrm{O}$ \\
Molar mass $(\mathrm{g} / \mathrm{mol})$ & 136.14 & 145.15 & 172.17 \\
Specific Gravity & 2.97 & $2.69-2.76$ & $2.31-2.33$ \\
Color & Colorless to pale blue & white & Colorless to white \\
Solubility in water $(\mathrm{g} / 100 \mathrm{ml})$ & 0.21 & n/a & 0.24 \\
\hline
\end{tabular}



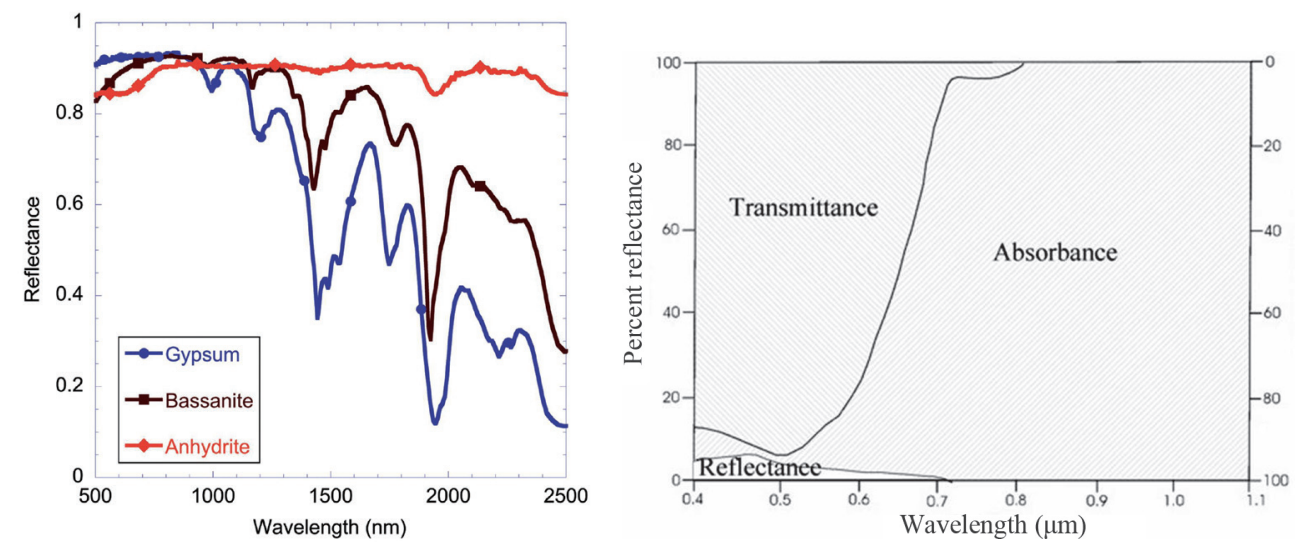

Fig. 1 (left). (Color online) Reflectances of bassanite and gypsum at different wavelengths.

Fig. 2 (right). Reflectance of water at different wavelengths.

In addition, adhesives with different viscosities were employed in the setting process to investigate the diffusion ratio and setting time of gypsum. Generally, cornstarch and water are mixed and used to make fake blood and simulate blood pressure and rate in vitro models. ${ }^{(19,20)}$ Therefore, cornstarch and water were blended and three different viscosities were designed to simulate blood or serum and employed as the adhesive in the $3 \mathrm{DP}^{\mathrm{TM}}$ system for clinical application. The viscosity of the initial cornstarch/water was measured using a viscometer (VISCOTECH, LVDV-1); the value was $441.4 \mathrm{mPas}$ (cP) at room temperature $\left(27^{\circ} \mathrm{C}\right)$. The three different dilution ratios of the initial cornstarch/ water and the water and four different types of adhesive used in the experiment are summarized in Table 2. In general, the viscosity of pure water is $1 \mathrm{cP}$, and that of blood is approximately $3-4 \mathrm{cP}$.

\subsection{Experimental setup and methods}

In the experiment, a Point Gray Flea2 mono camera (with a $12 \mathrm{~mm}$ focal length, F/1.4 CCTV lens, $170 \mathrm{~mm}$ working distance from powder) was employed to acquire the images of bassanite (powder, without adhesive) and gypsum (with adhesive). In addition, a set of ring light-emitting diode (LED) lights (75 mm working distance from powder) operating at four different light wavelengths and a set of light controllers were used to irradiate the working platform (which is the powder bed in the experiment), as shown in Fig. 3. The thickness of the powder bed was $0.5 \mathrm{~mm}$. The wavelengths of the LED lights were red-660 nm, NIR-890 nm, ultraviolet (UV)-405 nm, and white light, and the four light sources were switched on using the light controller, as shown in Figs. 4(a) and 4(b). During the setting process, the bassanite was bonded by the adhesive and became gypsum, and the components of the adhesive were the water and cornstarch/ water. 
Table 2

Components of adhesives and their properties.

\begin{tabular}{llc}
\hline No. & Component & Dilution ratio \\
\hline Type I & Water & \\
Type II & Cornstarch/Water & $1: 8$ \\
Type III & Cornstarch/Water & $1: 4$ \\
Type IV & Cornstarch/Water & $1: 2$ \\
\hline
\end{tabular}

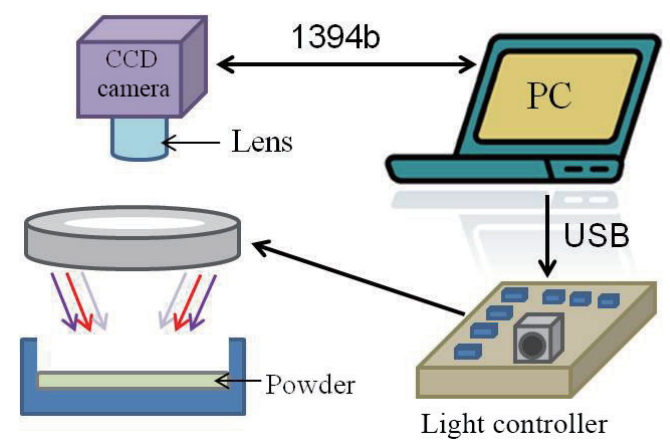

Fig. 3. (Color online) Schematic of the imaging system comprising the ring light with LEDs of four wavelengths.

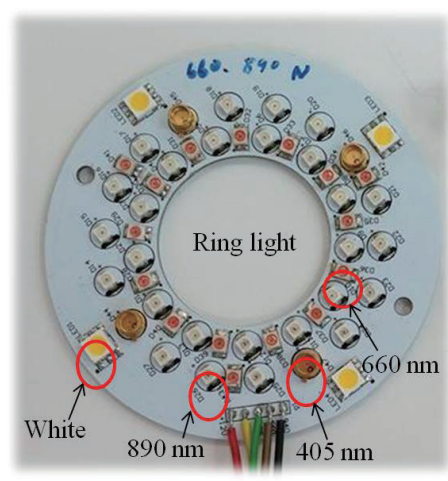

(a)

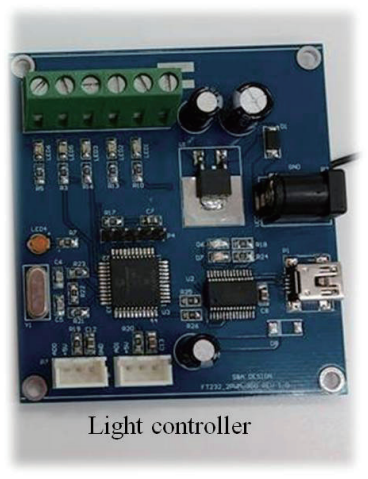

(b)

Fig. 4. (Color online) Layouts of (a) ring LED light and (b) light controller.

The contour of each model layer can be obtained from the difference between before and after adding the adhesive. The flowchart of the monitoring process in the 3DPTM system is shown in Fig. 5, which consists of six main steps for generating the model contour from the acquired images, detailed as follows.

Step I: The powder was placed on the working platform uniformly, and it was paved by an extremely smooth plate to ensure the integrity of the model in the printing process. 
(I)

(II)

(III)

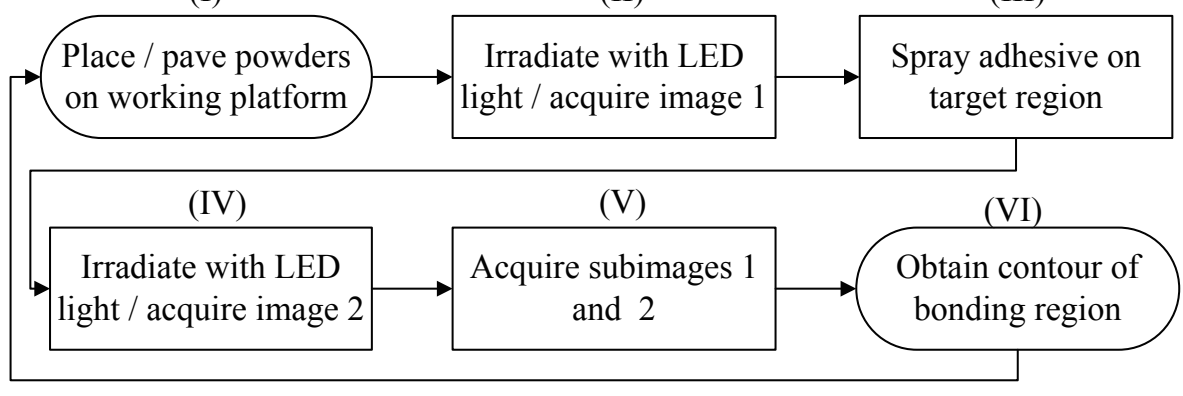

Fig. 5. Flowchart of monitoring process in the $3 \mathrm{DP}^{\mathrm{TM}}$ system.

Step II: The powder was irradiated with LED light and the powder image was acquired as a reference using a charge-coupled device (CCD) camera.

Step III: The adhesive was sprayed on the target region to bind the powder and form one layer of the model.

Step IV: LED Irradiation and image acquisition were carried out again to obtain the image of both powder and bonding model in working platform.

Step V: Two subimages, one before and one after adding adhesive and bonding, were obtained from the difference in intensity of the images.

Step VI: The contour of the bonding region was obtained and whether defects were produced during the bonding process was determined. After completing this step, Steps I through printing the next layer in Step III were repeated.

\section{Results and Discussion}

\subsection{Contours of model with different light irradiation wavelengths}

To obtain the contour between the bassanite (before adding adhesive) and the gypsum (after adding adhesive) accurately, four types of LED light with different wavelengths were employed to irradiate the working platform, and the images were acquired alternately. After acquiring the images, the intensities of the bassanite, [shown in Figs. 6(a)-6(d)] and gypsum [(shown in Figs. 6(e)-6(i)] at each wavelength in the same region were calculated, and the intensities were normalized to compensate for the variation of light brightness. The results show that the image contrast between the bassanite and the gypsum increases with decreasing light wavelength, and it has the largest intensity difference while being irradiated with UV-LED light, as shown in Fig. 7. The normalized intensity of gypsum was $92.4 \%$ of that of bassanite irradiated by $405 \mathrm{~nm}$ light, and the value was $94.5 \%$ while being irradiated by white light.

In addition, the smoother contour of gypsum can be observed owing to the lower reflectance after the bassanite absorbed the water, as shown in Fig. 8, and these results were similar to those of Harrison. ${ }^{(17)}$ Therefore, the UV-LED light will be employed as the light source in the real-time monitoring system in the $3 \mathrm{DP}^{\mathrm{TM}}$ process. 


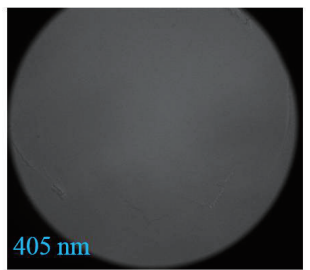

(a)

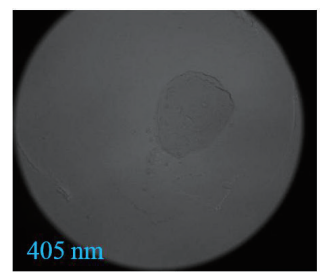

(e)

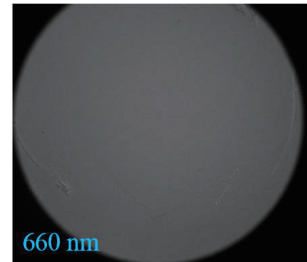

(b)

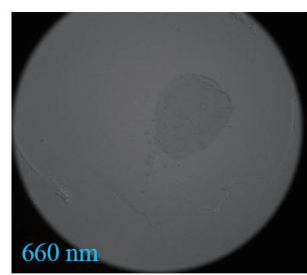

(f)

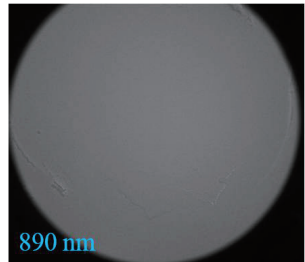

(c)

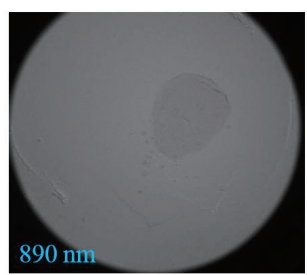

(g)

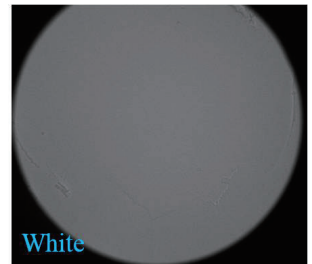

(d)

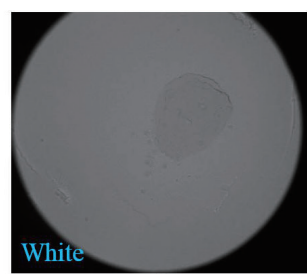

(h)

Fig. 6. (Color online) Images of (a)-(d) bassanite and (e)-(i) gypsum irradiated by different wavelengths of LED light.

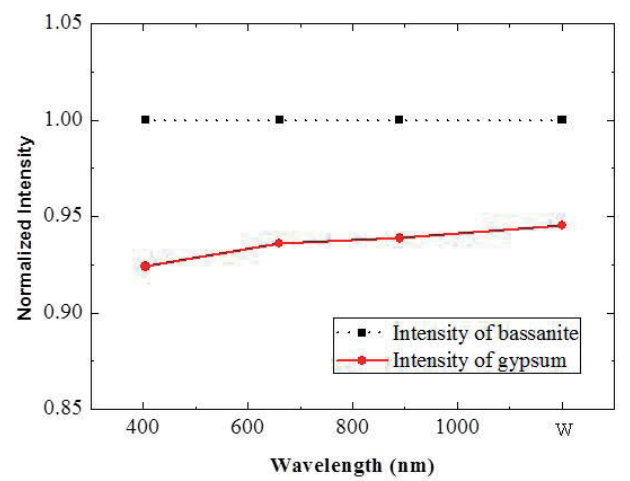

Fig. 7. (Color online) Normalized intensities of bassanite and gypsum at different light wavelengths.
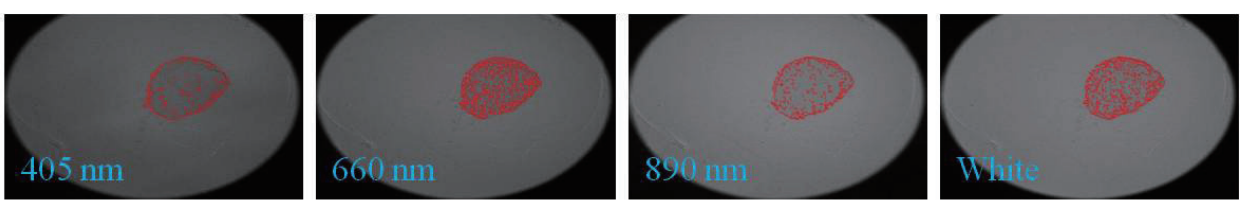

Fig. 8. (Color online) Contour of gypsum at different light wavelengths. 


\subsection{Contour variation and setting times in relation to adhesive volumes}

From these results, the UV-LED light was employed to irradiate the working platform, and the different volumes of adhesive were added to investigate the diffusion length and diffusion ratio in the setting process. In the experiment, the monitoring time was $500 \mathrm{~s}$ at intervals of $1 \mathrm{~s}$, and the component of the adhesive was water. The results show that the diffusion length in the diameter of the bonding region on a single axis corresponded to the volumes of adhesive that the diameter will diffuse; 3.7, 4.9, 5.7, and $7.8 \mathrm{~mm}$ were the initial sizes while the volumes were $0.025,0.05,0.075$, and $0.1 \mathrm{ml}$, respectively, as shown in Fig. 9(a). In addition, the relationship between the diffusion length and the volumes of adhesive can be fitted and expressed by a linear equation, shown in Fig. 9(b) and written as

$$
L_{\mathrm{d}}=56.52 \times V(a)+2.15,
$$

where $L_{\mathrm{d}}$ and $V(a)$ are the diffusion length of bonding region and the volume of adhesive, respectively. However, the diffusion ratio of the bonding region with four different volumes of adhesive approximately ranged from 1.33 to 1.41 times the initial size, and was 1.39 times the original size with $0.05 \mathrm{ml}$ of adhesive, as shown in Fig. 10.

In addition, the setting time of the model was determined when the normalized length of the bonding region can be controlled at $97.5 \%$ continuously. Figure 11 indicates that the lower adhesive volume caused the size of the bonding region to become saturated quickly; the model would be saturated and not diffused continuously in 220, 290, 310, and $430 \mathrm{~s}$, when four different volumes $(0.025,0.05,0.075$, and $0.1 \mathrm{ml}$, respectively) of adhesive were added in the powder bed.

\subsection{Contour variation in relation to adhesive viscosity}

To simulate the different viscosities of adhesive employed in the $3 \mathrm{DP}^{\mathrm{TM}}$ system, four types of adhesive with different viscosities were used to investigate the diffusion ratio

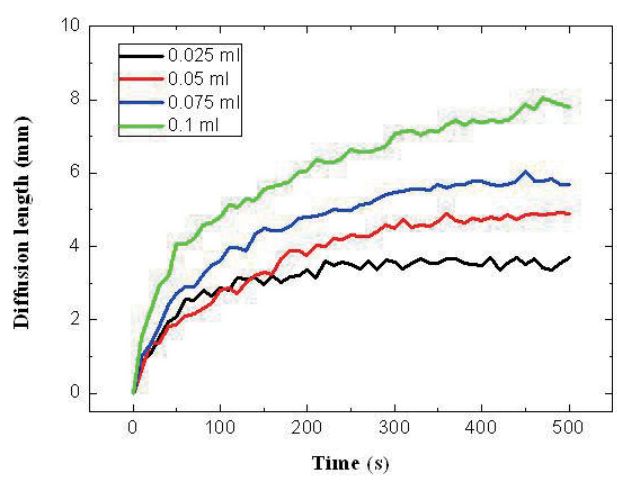

(a)

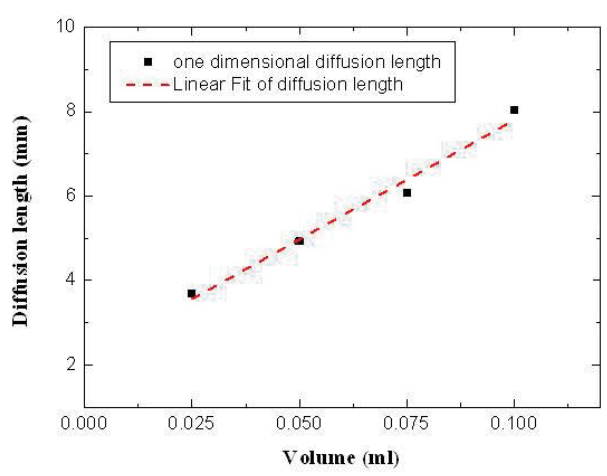

(b)

Fig. 9. (Color online) Diffusion length of bonding region in relation to (a) setting time and (b) adhesive volumes. 


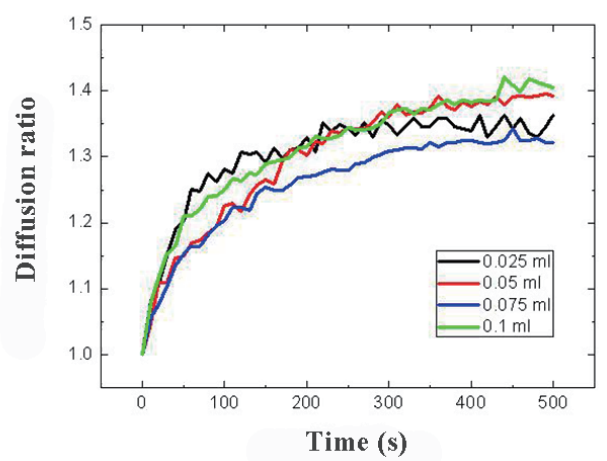

Fig. 10. (Color online) Diffusion ratio of bonding region with different adhesive volumes.

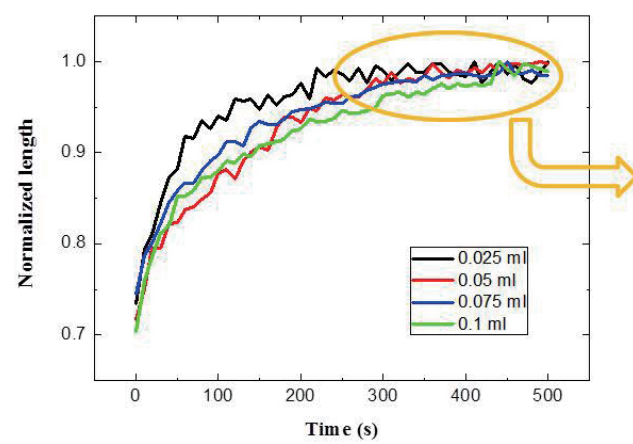

(a)

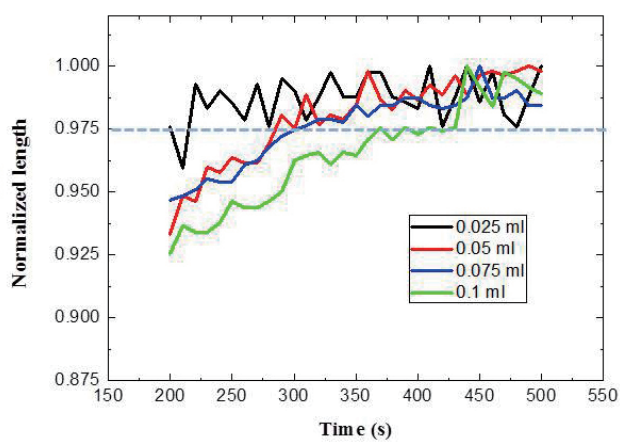

(b)

Fig. 11. (Color online) Normalized length of bonding region at different setting times.

and the setting time of the model. The results showed that the diffusion ratio increased and the setting time was extended when the viscosity of the adhesive increased (Type I to Type III); the diffusion ratio and setting time increased from 1.39 to 1.60 times and $290 \mathrm{~s}$ to $360 \mathrm{~s}$, respectively, as shown in Fig. 12(a) and as summarized in Table 3. The reason was that the cornstarch/water includes many micromolecules, and the micromolecules flow and cause better ductility than pure water. ${ }^{(21,22)}$ However, the adhesive flowed with difficulty and the diffusion ratio and setting time decreased when the adhesive (Type IV) was too thick. For the 3DP ${ }^{\mathrm{TM}}$ process, 2-3 layers of the model can be printed in $1 \mathrm{~min}$, so the diffusion ratio of the model in the initial $60 \mathrm{~s}$ was determined for computing the volumes of the adhesive, as shown in Fig. 12(b). The diffusion ratio was approximately 1.15-1.2 times with the Type II and III adhesives, and it was 1.1 times with the Type I adhesive in the initial $20 \mathrm{~s}$ of the setting process. From these results, the diffusion ratio of the model can be obtained and the volume of adhesive can be calculated and controlled to prevent model distortion in the $3 \mathrm{DP}^{\mathrm{TM}}$ process. 


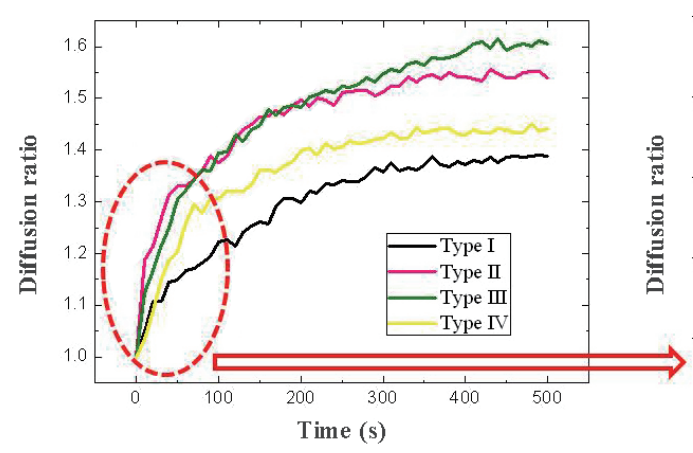

(a)

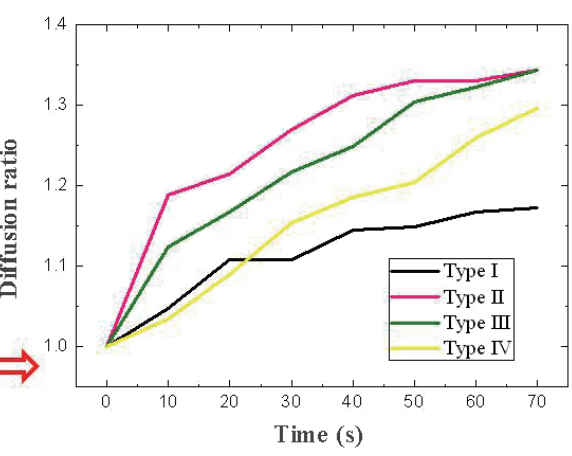

(b)

Fig. 12. (Color online) Diffusion ratio of bonding region with different viscosities of adhesive.

Table 3

Features of gypsum with four types of adhesive.

\begin{tabular}{lcc}
\hline No. & Diffusion ratio & Setting time (s) \\
\hline Type I & 1.39 & 290 \\
Type II & 1.54 & 310 \\
Type III & 1.60 & 360 \\
Type IV & 1.43 & 280 \\
\hline
\end{tabular}

\section{Conclusions}

By using the UV-LED as the light source of the real-time monitoring system for the $3 \mathrm{DP}^{\mathrm{TM}}$ process that modeled from bassanite and adhesive to gypsum, images with contrast substantially higher than those using light of other wavelengths can be obtained. In addition, a smoother contour of gypsum can be observed simultaneously. This study also showed that the diffusion length and setting time of the model increased with increasing adhesive volume; the setting time was $290 \mathrm{~s}$ when $0.05 \mathrm{ml}$ of adhesive (water) was added. However, the diffusion ratio of the model ranged from 1.33 to 1.41 times with four volumes of adhesive, which has high uniformity. In addition, the diffusion ratio and setting time increased with increasing viscosity of the adhesive because the micromolecules in the adhesive would flow and assist the adhesive diffusion; the setting time of $70 \mathrm{~s}$ can be extended when cornstarch/water was used. Therefore, the volume and viscosity of the adhesive and the diffusion ratio of the model should be considered and estimated to control the dimensions of a model and prevent distortion during the $3 \mathrm{DP}^{\mathrm{TM}}$ process. In the future, a real-time monitoring system can be built on the developed 3DP ${ }^{\mathrm{TM}}$ system for jawbone reconstruction and applied to monitor whether defects are generated during the $3 \mathrm{DP}^{\mathrm{TM}}$ process. 


\section{Acknowledgements}

This work was supported in part by the Ministry of Science and Technology, Taiwan, under Grant no. MOST 103-2218-E-038-002.

\section{References}

1 J. P. Kruth, M. C. Leu and T. Nakagawa: CIRP Ann. Manuf. Technol. 47 (1998) 525.

2 A. Bellini and S. Güçeri: Rapid Prototyping J. 4 (2003) 252.

3 C. X. F. Lam, X. M. Mo, S. H. Teoh and D. W. Hutmacher: Mater. Sci. Eng., C 20 (2002) 49.

4 B. Mueller and D. Kochan: Comput. Ind. 39 (1999) 47.

5 M. N. Cooke, J. P. Fisher, D. Dean, C. Rimnac and A. G. Mikos: J. Bio. Mater. Res. B 64B (2003) 65.

6 K. Osakada and M. Shiomi: Int. J. Mach. Tool. Manu. 46 (2006) 1188.

7 A. Khalyfa, S. Vogt, J. Weisser, G. Grimm, A. Rechtenbach, W. Meyer and M. Schnabelrauch: J. Mater. Sci.: Mater. Med. 18 (2007) 909.

8 F. Rengier, A. Mehndiratta, H. von Tengg-Kobligk, C. M. Zechmann, R. Unterhinninghofen, H. U. Kauczor and F. L. Giesel: Int. J. Comput. Assist. Radiol. Surg. 5 (2010) 335.

9 G. Yang, J. Liu, F. Li, Z. Pan, X. Ni, Y. Shen, H. Xu and Q. Huang: Mater. Sci. Eng., C 35 (2014) 70.

10 A. Sugaware, K. Asaoka and S. J. Ding: J. Mater. Chem. B 1 (2013) 1081.

11 A. J. Ambard and L. Mueninghoff: J. Prosthodont 15 (2006) 321.

12 H. Guo, J. Wei and C. S. Liu: Biomed. Mater. 1 (2006) 193.

13 A. Gisep and B. Rahn: Eur. Cells Mater. 7 (2004) 34.

14 V. Chovancova-Lovell, A. Pekarovicova and P. D. Fleming III: J. Imaging Sci. Technol. 50 (2006) 550 .

15 B. Derby: Annu. Rev. Mater. Res. 40 (2010) 395.

16 J. L. Bishop, M. D. Lane, M. D. Dyar, S. J. King, A. J. Brown and G. Swayze: Am. Mineral. Sep. 25 (2013).

17 T. N. Harrison: Am. Mineral. 97 (2012) 598.

18 S. Farooq: Spectral Reflectance of Land Covers, http://www.geol-amu.org/notes/m1r-1-8. $\mathrm{htm}$.

19 S. E. Mcllhenny: United States Patent No. 20140243181 A1 (2014).

20 T. Cao, S. M. Shapiro, M. M. Bersohn, S. C. K. Liu and L. E. Ginzton: J. AM. Coll. Cardiol. 22 (1993) 271.

21 H. C. Chang, C. I. Lin, W. C. Say, H. W. Pan and S. Lin: United States Patent No. 2003/0129256 A1 (2003).

22 X. Yu, A. R. Schmidt, L. A. Bello-Perez and S. L. Schmidt: J. Agric. Food Chem. 56 (2008) 50. 